\title{
Production And Fusion Of Antimicrobial Agents With Bio Plastic Using
}

\section{Palmyra Sprout}

\author{
${ }^{1}$ K.Madhanasundareswari, Associate Professor \& Head, Department of Microbiology, Sri \\ Ramakrishna College of Arts \& Science for Women, Coimbatore, India \\ ${ }^{2}$ Reshmi Gopalakrishnan, Assistant Professor, Sri Ramakrishna College of Arts \& Science for \\ Women, Coimbatore, India \\ ${ }^{3}$.K.Gayathri, M. Sc., Microbiology, Sri Ramakrishna College of Arts \& Science for Women, \\ Coimbatore, India
}

\begin{abstract}
The problems linked to plastic wastes have led to the development of biodegradable plastics. More specifically, biodegradable bioplastics are the polymers that are mineralized into carbon dioxide, methane, water, inorganic compounds, or biomass through the enzymatic action of specific microorganisms. They could, therefore, be a suitable and environmentally friendly substitute to conventional petrochemical plastics. The physico-chemical structure of the biopolymers, the environmental conditions, as well as the microbial populations to which the bioplastics are exposed to are the most influential factors to biodegradation. The Borassus flabellifer is a tall and erect palm, with large, fan-shaped leaves which are quite unlike the pinnate leaves of other palms. Borassus is from a Greek word describing the leathery covering of the fruit and flabellifer means "fan bearer". In recent years, India stands first in the world in terms of its wealth of Palmyra (Borassus flabellifer population nearly 122 million palms. In this study overall purpose was to investigate the utilization of food industry wastes in order for the bioplastic production. To achieve this objective the production of bioplastic from palmyra sprout investigated. In addition, some properties of produced bioplastic such as water, absorption capacity, solubility and biodegradability, characterisation studies were analysed.
\end{abstract}


Keywords: Bioplastics, Borassus flabellifer, Biodegradability, Spectroscopic analysis, environment

\section{INTRODUCTION}

Plastics are a large family of polymers, traditionally derived from fossil resources that are characterised as having a broad range of properties and characteristics [1]. Approximately $90 \%$ of plastics produced are derived from fossil feedstocks [2]. Currently, plastic production accounts for approximately $4-8 \%$ of oil consumption globally, and this is expected to reach $20 \%$ by $2050[3,4]$. Ever since their wide scale production in the 1950 s, plastics have permeated society due to their use in a wide range of applications [5]. The success and continued growth of plastics can be attributed to their low prices, durability, strength to weight ratios, and contributions to the ease of everyday life [6]. With their low cost coupled with a wide range of properties, global plastic production has steadily increased from 15 million metric tonnes in 1964 to 359 million metric tonnes in 2018 , with a projected 2-fold increase within the next 20 years [7, 8]. Plastics have contributed greatly to the ease of everyday life as a result of their large-scale utility and their global presence as packaging materials for the collection and storage of drinks and food. The plastic industry is important for employment, it is reported that over 1.6 million people employed in the industry across the EU, and the $€ 360$ billion turnover in 2018 [9]. Furthermore, the high strength to weight ratio of plastics allows us to reduce the transport costs of goods. For instance, the use of polyethylene terephthalate (PET) bottles over glass counterparts has been noted to reduce energy consumption associated with transport by $52 \%$ in Europe [10,11].

Thermoplastics such as polyethylene terephthalate (PET), polyethylene (PE), polypropylene (PP), and polystyrene (PS) make up a total of $60 \%$ of the overall plastic demand in Europe [12]. While these plastics are traditionally petrochemically derived, there is a growing 
demand for the production of plastics using renewable resources (so called "bioplastics") as alternatives to their petrochemically derived counterparts (Figure 1). All bioplastics are produced starting from natural resources. However, not all are biodegradable [13]. Bioplastics are a family of plastics that can be divided into two categories, biodegradable and non-biodegradable (Table 1). The diversity of biodegradable bioplastics is found in the variation in biodegradation rates and routes. Such plastics include polylactic acid (PLA), polyhydroxyalkanoates (PHA), cellulose, and starch. Similarly to oil-based plastics, biodegradable biobased plastics can be recycled or incinerated, but they are not widely recycled, as they are seen as contaminants in the current recycling system. They may also be microbially degraded, allowing for alternative endof-life management, such as industrial and home composting, anaerobic digestion, depending on the plastics' type, facilitating the development of a circular economy [14,15]. Non-biodegradable bioplastics include bio-polyethylene terephthalate (bio-PET), polyol-polyurethane, and biopolyethylene (Bio-PE).

Palmyra palm is a 'miracle' plant due to the once wide utilization of most of its parts, such as the trunk, fruit, and flesh. The trunk can be used for furniture and handicrafts. Palmyra tuber has $98 \%$ fiber which means up to $95 \%$ is starch content. They are separated by hand beating or crushing mechanically and then by removing the pitch using the device called comber.

\section{METHODOLOGY}

\section{Collection of samples}

Palmyra sprout were purchased from the local market in Coimbatore. Analytical grade hydrochloric acid and glycerol, citric acid, sodium hydroxide, agar, sodium alginate, gelatin was purchased in lab.

\section{Preparation of palmyra sprout from starch}


The palmyra sprout is cleaned. Approximately $25 \mathrm{~g}$ of palmyra sprout were placed into a beaker containing $800 \mathrm{ml}$ of water and boiled for 30 minutes. The water was decanted off and palmyra sprout were left to dry for 30 minutes at room temperature. The sample was placed in a clean 500ml beaker using hand blender the sample was squashed until uniform paste obtained.

\section{Production of bio plastic film from palmyra sprout}

To about $25 \mathrm{~g}$ of palmyra sprout paste is placed in 3 different beakers. About $2.6 \mathrm{ml}$ of $(0.5 \mathrm{~N}) \mathrm{HCL}$ is added to this mixture and stirred using glass rod. Then $2 \mathrm{ml}$ of $60 \%$ glycerol solution was added and the mixture was stirred. A $3 \mathrm{ml}$ of $90 \%$ citric acid was then added and citric acid and water were used as co plasticizer, and the mixture was stirred again. Then $3 \mathrm{ml}$ of $(\mathbf{0 . 5 N})$ NAOH was added to the mixture and stirred. The mixture was poured into a mould and spread into a thin layer with a glass rod. The mould was then placed in a room temperature for 48 hours.

\section{Glycerol as a Plasticizer}

Plasticizers or dispersants are additives that increase the plasticity or fluidity of a material. The dominant applications are for plastics, especially polyvinyl chloride (PVC) glycerol, sorbitol. The properties of other materials are also improved when blended with plasticizers including concrete, clays, and related products. Plasticizers make it possible to achieve improved compound processing characteristics, while also providing flexibility in the end-use product.

\section{Fabrication process}

In this experiment there were two compositions prepared. First is a mixture of starch and glycerol, Secondly a blend of starch powder, glycerol, and citric acid. Basically, starch (25\% amylose) was used in the experiment. The starch was plasticized with glycerol (95\% purity) 
while citric acid and water were used as a co-plasticizer. The material ratios and glycerol-monostearate was added as a lubricant.

\section{CHARACTERAZITATION STUDY}

\section{XRAY diffraction}

The gold nano particles of Palmyra sprout root were purified and go t pure crystals. The composition of nano particles were analysed by XRD.

\section{Scanning electron microscopy (SEM) and EDAX analysis}

Scanning electron microscopy (SEM) analysis was done by using VEGA3TESCAN machine. The characterization of the sample was conducted with an XRD 6000 X-ray diffractometry (shimadzu, Japan) operated at voltage of $40 \mathrm{kV}$ and current of $30 \mathrm{~mA}$ with $\mathrm{cu} \mathrm{k}$ radiation in $\theta 20$ configurations.

\section{TEM analysis}

The morphological analysis of the nanoparticles were done with transmission electron microscopy (TEM). The size and shape of the sample was determined by TEM. A drop of aqueous silver nanoparticle sample was loaded on carbon-coated copper TEM grid. The TEM micrograph images were recorded on a JEOL 1200 EX instrument on carbon coated copper grids with an accelerating voltage of 100 to $200 \mathrm{kV}$. The clear microscopic views were observed and documented in different ranges of magnifications. The presence of silver elements was confirmed through Energy Depressive spectroscopy.

\section{WATER APSORPTION TEST}

A small piece of the sample was cut into $1 \mathrm{~cm} \times 2 \mathrm{~cm}$ size. The initial weight of the sample was recorded. The sample was then placed into a beaker containing $60 \mathrm{~mL}$ of water at 
room temperature for 24 hours. The sample was then taken out from the water and wiped off. The final weight was recorded.

\section{Moisture content}

The dried sample was finally milled using pulveriser to pass through $250 \mu \mathrm{m}$ sieves. The samples were then packaged in polyethylene bag moisture was determined by the following equation:

$$
\text { Moisture }(\% \text { wet basis })=(\mathrm{M} 1 \mathrm{M} 2) / \mathrm{M} 1 \mathrm{X} 100
$$

\section{Fourier Transform Infrared Spectroscopy (FTIR) Characterization}

The IR spectra were measured with a Nicolet 210 spectrophotometer (Nicolet Co., USA). TPS was cut into small pieces, milled and diluted with $\mathrm{KBr}$ powder. The spectra were taken in 256 scans between 4000 and $400 \mathrm{~cm}-1$ with a resolution of $4 \mathrm{~cm}-1$.

\section{Swelling test}

Swelling test is generally conducted to check whether developed materials retain the original properties after formation by following the procedure. A pre-weighed piece of sample was used to check the protuberance and other morphological changes. The sample was immersed in various solvents such as water, chloroform, and methanol medium in different test tubes for about 2 hours and the results were recorded accordingly.

\section{Solubility test}

The bio plastic material prepared was studied for their solubility. The sample was cut into small pieces and was inserted into different test tubes containing different solvents - ammonia, acetic acid, acetone, sulphuric acid and ethyl alcohol. The solvents were chosen in such a way that the activity of material with parameters like high acidic solvent, polar solvent, non-polar solvent and weak acid were determined. 
Solubility $(\%)=$ weight $(\mathrm{g})$ of supernatant after drying $\mathrm{x} 100 /$ weight $(\mathrm{g})$ of sample.

The hygroscopicity $(\%)$ property of the sample powders was determined according to Cai and Corke (2000) with some modifications.

\section{DEGARADABILITY TEST}

To about 1.1 gram of pre weighed piece of bio plastic material 1 were taken and it was placed under the plate containing soil from the surface. Some amount of water was sprinkled on the soil so that bacterial enzymatic activities could be enriched. These samples were kept in the plate for about 15days and each three day of interval we observed the decrease in the weight of bio plastic material and results were recorded accordingly.

\section{PREPARATION OF STARCH FROM BORASSUS FLABELLIFER;}

The result of preparation of palmyra sprout from starch was depicted in plate. The result of the study showed that the extracted potato starch was brown in color.

\section{PRODUCTION OF BIOPLASTIC FLIM FROM BORASSUS FLABELIFER;}

The result of formation of bioplastic film from palmyra sprout starch was depicted in plate. The result of the study revealed that the bioplastic formed was brown in color.

\section{WATER ABSORPTION TEST}

Water resistance is an important characteristic in determining a suitable source for bioplastic. The water absorption of the plasticized starch BP film was carried out at room temperature for 24 hours to obtain the maximum water uptake data.

TABLE 1: WATER ABSORPTION TEST

\begin{tabular}{|c|c|c|}
\hline SAMPLE & TENSIL PROPERTY AVERAGE & WATER ABSORPTOIN \\
(borasuss flabellifer) DIFFERENT & MAXIMUM LOAD(N) & WATER UPTAKE $\%$ \\
\hline
\end{tabular}




\begin{tabular}{|l|l|l|}
\hline \multicolumn{1}{|c|}{ ANTIMICROBIAL AGENTS } & & \\
\hline Gelatin & 1.30 & 2.42 \\
\hline Sodium alginate & 1.21 & 2.61 \\
\hline agar & 1.15 & 2.43 \\
\hline
\end{tabular}

\section{SWELLING TEST SYTHESIS OF BIOPLASTIC FROM BORASUSS FLABELLIFER:}

The results of the swelling test of bio plastic of (Borasuss flabellifer) were shown in (plate $\mathrm{a}$, table $\mathrm{b}$ and $\mathrm{c}$ ). The results of the study showed that there was not much change in sample when it was soaked in chloroform and methanol, but slight increase in weight was observed when it was kept in water medium. The result from swelling test shows that low amount of engorgement in water which is more desirable to be a bio plastic material.

TABLE 2: SWELLING TEST

\begin{tabular}{|c|l|c|c|c|}
\hline & & INITIAL & FINAL & $\begin{array}{c}\text { DIFFERENCE } \\
\text { WEIGHT } \\
\end{array}$ \\
& Water & 0.14 & 0.35 & 0.21 \\
\hline & Chloroform & 0.14 & 0.20 & 0.06 \\
\hline Agar & Wethanol & 0.14 & 0.15 & 0.01 \\
\hline & Water & 0.16 & 0.26 & 0.1 \\
\hline Sodium Alginate & Chloroform & 0.16 & 0.18 & 0.11 \\
\hline & Methanol & 0.16 & 0.27 & 0.29 \\
\hline & Water & 0.13 & 0.42 & 0.17 \\
\hline Gelatin & Chloroform & 0.13 & 0.30 & 0.19 \\
\hline
\end{tabular}




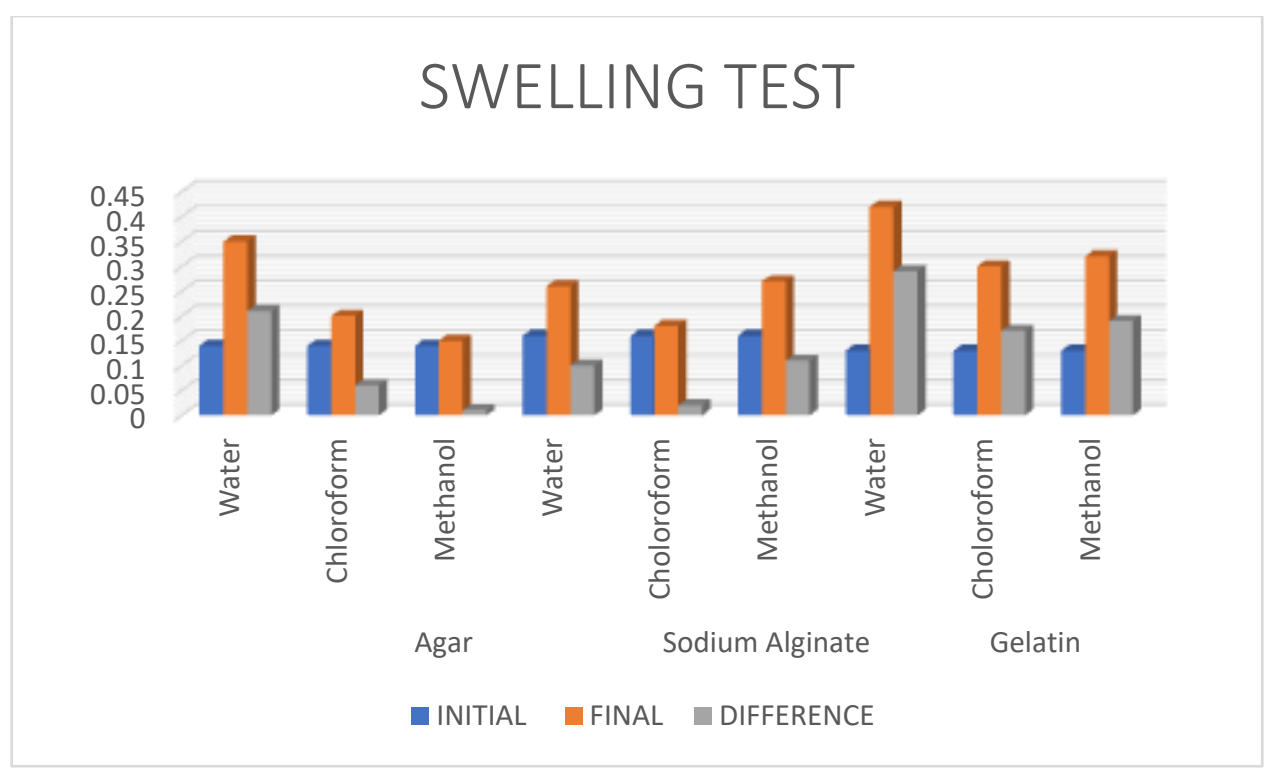

\section{SOBULITY TEST FOR BIOPLASTIC FROM BAROSUSS FLABELLIFER:}

The results of solubility test of bio plastics (palmyra sprout) were shown in the results of the study revealed that the material was insoluble in water which makes it more eligible to be a bio plastic material. It was also insoluble in acetone (polar solvent), ethyl alcohol (nonpolar solvent), acetic acid (polar solvent) and partially soluble in ammonia (polar solvent) and completely soluble in sulphuric acid (strongly acidic solvent\}. Solubility plays a major role in selecting a sustainable biomaterial for bio plastic because if the material is soluble in water and other solvents then it cannot be accounted as bio plastic. Results from the solubility test showed that the material is insoluble in water and other organic solvents which makes it more efficient to produce bioplastic at low cost.

TABLE 3: SOLUBILITY TEST

\begin{tabular}{|c|c|c|c|c|}
\hline Solvent & Sample & Insoluble & Partially & $\begin{array}{c}\text { Completely } \\
\text { Soluble }\end{array}$ \\
\hline \multirow[t]{3}{*}{ Ammonia } & Sodium Alginate & - & Yes & - \\
\hline & Gelatin & - & Yes & - \\
\hline & AGAR & - & Yes & - \\
\hline \multirow[t]{2}{*}{ Acetic Acid } & Sodium Alginate & Yes & - & - \\
\hline & Gelatin & Yes & - & - \\
\hline
\end{tabular}




\begin{tabular}{|c|c|c|c|c|}
\hline & AGAR & Yes & - & - \\
\hline \multirow[t]{3}{*}{ Chloroform } & Sodium Alginate & - & - & - \\
\hline & Gelatin & Yes & - & - \\
\hline & AGAR & - & Yes & - \\
\hline \multirow[t]{3}{*}{ Acetone } & Sodium Alginate & Yes & Yes & Yes \\
\hline & Gelatin & Yes & - & - \\
\hline & AGAR & - & Yes & - \\
\hline \multirow[t]{3}{*}{ Methanol } & Sodium Alginate & - & Yes & - \\
\hline & Gelatin & Yes & - & - \\
\hline & AGAR & - & Yes & - \\
\hline \multirow[t]{3}{*}{ Ethyl Alcohol } & Sodium Alginate & Yes & - & - \\
\hline & Gelatin & Yes & - & - \\
\hline & AGAR & Yes & - & - \\
\hline
\end{tabular}

\section{DEGRADATION TEST}

TABLE 4: DEGRADATION TEST

\begin{tabular}{|c|l|c|c|c|c|c|}
\hline \multirow{3}{*}{$\begin{array}{c}\text { Different } \\
\text { Samples }\end{array}$} & \multicolumn{1}{|c|}{ Bioplastic } & $\mathbf{3}^{\text {rd }}$ Day & $\mathbf{6}^{\text {th }}$ Day & $\mathbf{9}^{\text {th }}$ Day & $\mathbf{1 2}^{\text {th }}$ Day & $\mathbf{1 5}^{\text {th }}$ Day \\
\cline { 2 - 7 } & Sodium Alginate & 0.65 & 0.60 & 0.54 & 0.66 & 0.42 \\
\cline { 2 - 7 } & AGAR & 0.89 & 0.74 & 0.66 & 0.50 & 0.50 \\
\cline { 2 - 7 } & Gelatin & 0.73 & 0.69 & 0.50 & 0.41 & 0.47 \\
\hline
\end{tabular}

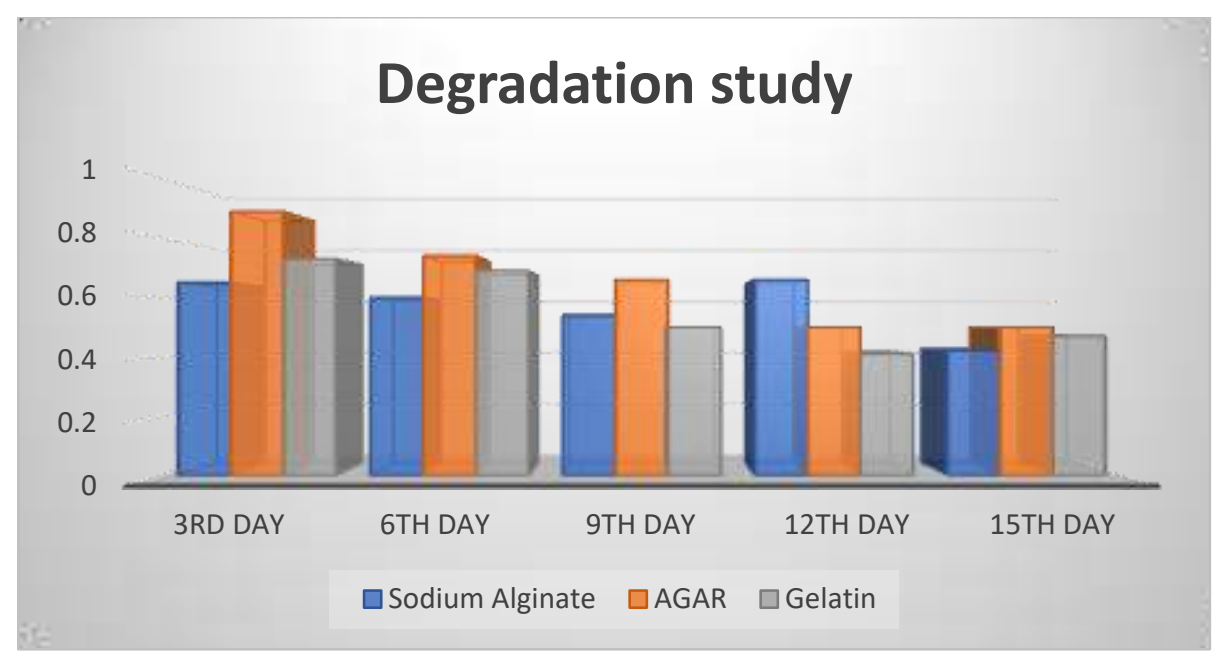

There was a reduction in the thickness of the bio plastic. The bio plastic from banana peel turned into bit dark colour and the bio plastic from Palmyra sprout starch became bit soft and also the colour of the bio plastic disappeared turning from brown to slight white. The bio plastic kept in the plates were biodegradable (Table 1), as per our results there were reduced in the weights of 
Palmyra sprout starch plastics are very much desired properties for the typical bio plastic. However, there is a big gap in identifying the biodegradable tractable factor in synthesizing bio plastic material, so the current report will be helpful in finding the possible solution to the environmental tractability of biomaterials.

\section{Fourier transforms infrared spectroscopy (FTIR)}

The result of FTIR analysis of synthesized bio plastic from potato starch was depicted in figure 1. The result of FTIR analysis of the sample showed that FTIR spectrum of the sample was obtained at the wavelength in the range of (400-4000nm). . Meanwhile, the major absorption bands in the raw extract's spectrum were attributed to various functional groups. The peak at $3443.26 \mathrm{~cm}-1,37.96 \% \mathrm{~T}$ is attributed to $\mathrm{O}-\mathrm{H},-\mathrm{NH}$ group of terpenoids, alkaloids other alcohols and phenols, the peak at $2929.48 \mathrm{~cm}-1,46.06 \% \mathrm{~T}$ is probably due to sp3 $\mathrm{C}-\mathrm{H}$ bond stretching, the peak at $1651.28 \mathrm{~cm}-1,48.20 \% \mathrm{~T}$ is possibly due to $\mathrm{C}=\mathrm{O}$ or $\mathrm{C}=\mathrm{N}$ groups in alkaloids and terpenoids, while the peaks at $1384.14 \mathrm{~cm}-1,47.36 \% \mathrm{~T}$ and $1162.66 \mathrm{~cm}-1,40.62 \% \mathrm{~T}$ are probably due to $\mathrm{C}-\mathrm{H}$ rock bending vibration and $\mathrm{C}-\mathrm{C}$ stretching in terpenoids, respectively.

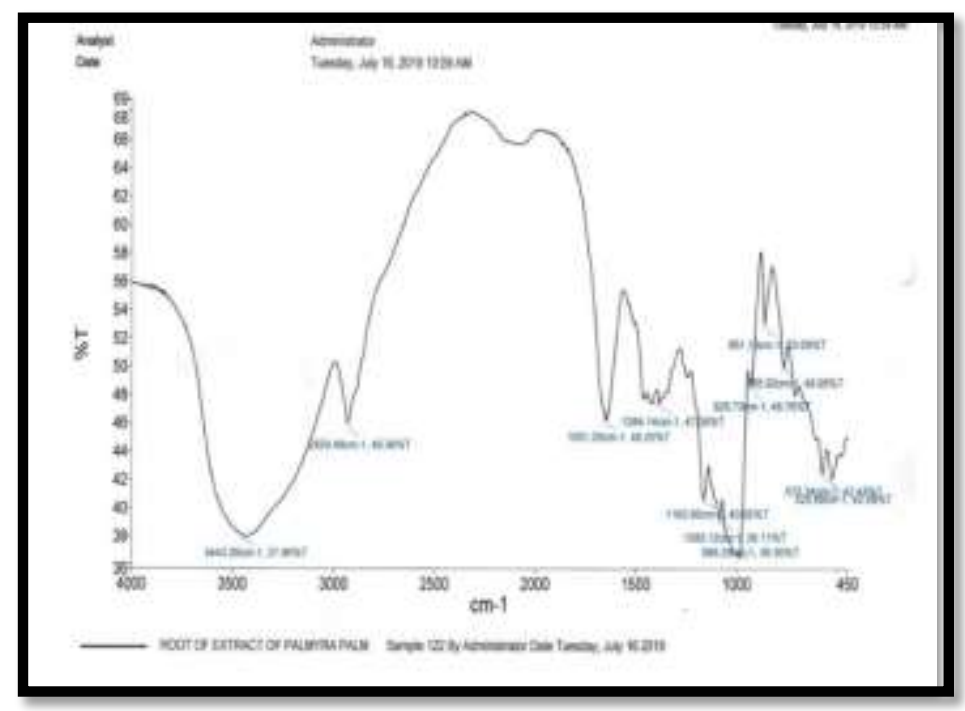

FIGURE 1: FTIR SPECTROSCOPIC ANALYSIS 


\section{MOISTURE CONTENT}

Moisture provides a measure of the water content of the palmyra pulp powder and for that matter its total solid content. It is also an index of storage stability of the pulp powder. The moisture content of the pulp powder is $74-77 \%$.

\section{SEM analysis}

To determine the shape, size and distribution of the particles, SEM Images were also recorded. Monodispersed spherical particles were formed on the surface of BPE derived biological materials. The image obtained by the SEM also showed spherical particles confirming the result obtained by SEM.

\section{TEM analysis}

In order to evaluate the morphology and size, TEM experiment was carried out. TEM image figure 2 revealed that palmyra sprout was poly- dispersed and non-aggregated in nature. It is important to mention here is that, size of the particles varies from 5-15 nm.

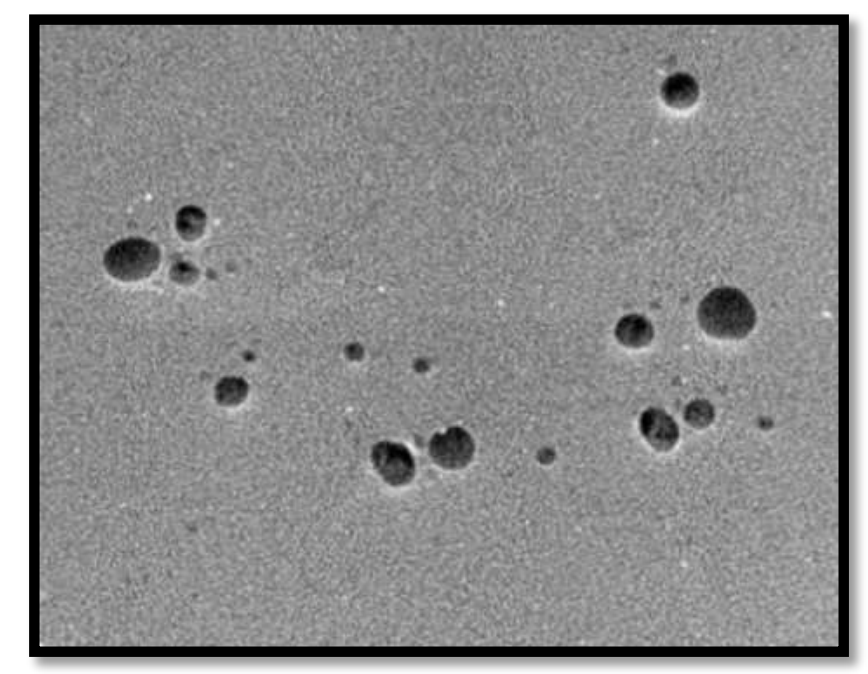

FIGURE 2: TEM ANALYSIS 


\section{XRD Diffraction studies}

The crystalline nature of Palmyra sprout particles was confirmed by the analysis of XRD pattern as shown in figure 3. The four distinct diffraction peaks at $2 \theta$ values of $38.15^{\circ}, 44.30^{\circ}, 64.53^{\circ}$ and $76.96^{\circ}$ can be indexed to the (llll 111$),\left(\begin{array}{lll}2 & 0 & 0\end{array}\right),\left(\begin{array}{lll}2 & 2 & 0\end{array}\right)$ and $\left(\begin{array}{lll}3 & 1 & 1\end{array}\right)$ reflection planes of face centred cubic structure. In addition to the Bragg peaks representative additional peaks were also observed at $27.89^{\circ}, 32.24^{\circ}, 46.26^{\circ}$, and $54.79^{\circ}$.

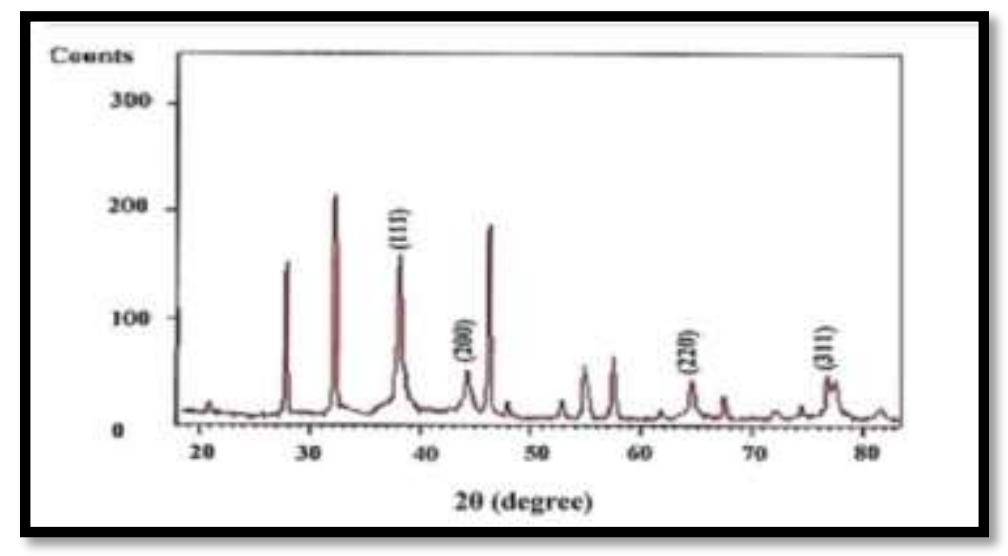

FIGURE 3: XRD DIFFRACTION PATTERN

\section{CONCLUSION}

Plastic is being produced from organic compounds like crude oil, natural gas and so on. During the production of plastics, some toxic chemicals such as acetone, methylene, chloride, styrene, benzene, sulphur oxides, nitrogen oxides, methanol etc. and also some volatile organic compounds are frequently released. These toxic acids cause serious environmental pollution.

\section{REFERENCES}

1. Anita Ivankovic ,StainslavaTaric , 2019 ; Biodegradable packing in food Industry. Journal of food safety and Quality 68 : 23-52.

2. AzahariaN , Othman N , Ismail k, 2011 ; Biodegradation studies of polyvinyl alcohol corn starch blend films in solid and solution media. J.phy. sci . 22: 15-31. 
3. AbindinM.Z ,julkapli N.M , Juahir H ,Azaman F ,AND Suliman N .H 2015; Fabrication properties of chitosan with starch for packing applications. Malays . J. Anal sci .10321042.

4. Borgers J ,2015 ;Infuenced of different starch sources and plastidicer on properties of Bio degradable film.Int, Food .Res , 22; 2346-2357.

5. Bolt HM ,2005 ; Vinyl chloride - A classical Industrial Toxicant of new Interest. Critical review in toxicology . 35: 307-323.

6. Chen L , 2017 ; Preparation method of potato starch- based degradable plastic film . CN104292479 A.

7. Cao X ,chen L, chang P.R , Muri A, 2008 ; Starch based nanocomposites reinforced with flax cellulose nanocrystals, Express polymer letter, 2; $502-510$.

8. ChiclliniE ,Corti A D, Antone S , Solaro R , 2003 ; Biodegradation of polyvinyl alcoholbased materials progress in polymer science. 28: 963-1014.

9. Davis A B , Song J H , 2006 ; Biodegradable packging based on raw materials from crops and their impact on waste management. In crop prod, 23 : 147-61.

10. Emadian S M ,Onay T T , Demird B , 2017 ; Biodegradable of bioplastic in natural environments. Waste management, 59: 526-536.

11. EdhirejA ,Sapuan S M , Jaweid M , Zahari N I , 2017 ; Its polymer , fiber , composite and application. Polym. Compos ,38: 555-570.

12. FakhouriFm, Matelli S M , Cano T, Velasco J I, Mei . L. H. I ,2013 ; Comparative study of processing method for starch/gelatin in films. Carbohydr.polym.95, 681-689.

13. Falgues V, Quintero J P , Jimene Z A , Munoz J A , Ibarz ,2011 ; Edible film and coatings structural active functions and trends in their uses. Trends Food sci.Technol.22 : 292-303. 
14. Garima Goswani , Priyanka Purobit , Manisha Givi , 2015 ; Bioplastic from organic waste. International Journal of Engineering Research and Technology.2278-0181.

15. GhanbarzodeshB ,Alamasi H , Entezami A A , 2011 ; Improving barrerier and mechanical properties of corn starch and based edible films. Effect of citric acid and carboxymethyl cellulose. Industrial crops and product. 33: 229-235. 